\title{
HUBUNGAN TIPE KEPRIBADIAN DENGAN KINERJA PERAWAT DI RUANGAN RAWAT INAP RSU GMIM BETHESDA TOMOHON
}

\author{
Morits G. Kosegeran \\ Damayanti H. Pangemanan \\ Rivelino S. Hamel
Program Studi Ilmu Keperawatan Fakultas Kedokteran
Universitas Sam Ratulangi
Email : morits.g.kosegeran@gmail.com

\begin{abstract}
Abstrack : Since the development of society's knowledge is increasing rapidly, especially their knowledge of health, cmpetency has become an absolute requirement for nurses in providing health services. The quality of services have to be maintained in order to provide an excellent services. The performances of people in doing their work is always based on what personality they have which might affects the result of each works they do. The aimof this research is to know the relation between types of personality and nurse' performances in the ward of GMIM Bethesda Public Hospital Tomohon. Research methods this research design uses a crosssectional approach and purposive sampling technique with 62 respondents. Data are collected by questionnaires.The Result isis using chi square in the level of significant $95 \%$ results $p$ values $=0.000<0.05$. Conclusion this research shows that there is a relation between types of personality and nurse' performances in the ward of GMIM Bethesda Public Hospital Tomohon.

Key words: Types Of Personality, Performance, Nurse
\end{abstract}

\begin{abstract}
Abstrak : Kinerja perawat menjadi hal yang vital dalam peningkatan kualitas pelayanan yang ada pada sebuah instansi penyedia layanan kesehatan, dilihat dari data yang ambil sebagian pasien mengatakan perawat yang bekerja di RSU GMIM Bethesda Tomohon memiliki pembawaan yang ramah dalam berkomunikasi dan ada juga yang sebaliknya, hal tersebut dikarenakan perbedaan corak kepribadian seseorang yang nampak pada perilaku seorang perawat ketika berinteraksi dengan pasien.Tujuan penelitian ini adalah mengetahui hubungan tipe kepribadian dengan kinerja perawat di ruangan rawat inap RSU GMIM Bethesda Tomohon. Metode penelitian ini adalah cross sectional, teknik sampling dalam penelitian ini adalah total samplingberjumlah 62 responden. Pengumpulan data menggunakan kuesioner untuk mengukur tipe kepribadian dan kinerja perawat. Hasil Uji dengan menggunakan uji Chi Square pada tingkat kemaknaan $95 \%$ diperoleh nilai signifikan $p=0.000$ atau lebih kecil dari $0.05(0.000<0.05)$. Kesimpulan ada hubungan tipe kepribadian dengan kinerja perawat di ruangan rawat inap RSU GMIM Bethesda Tomohon.

Kata kunci :Tipe Kepribadian, Kinerja, Perawat.
\end{abstract}




\section{PENDAHULUAN}

$\begin{array}{ccr}\text { Rumah } & \text { Sakit adalah institusi } \\ \text { pelayanan } & \text { kesehatan } & \text { yang }\end{array}$ menyelenggarakan pelayanan kesehatan perorangan secara paripurna yang menyediakan pelayanan rawat inap, rawat jalan, dan gawat darurat. Persaingan yang semakin ketat akhir-akhir ini menuntut sebuah lembaga penyedia jasa untuk selalu memanjakan pelanggan dengan memberikan pelayanan terbaik. Para pelanggan akan mencari produk berupa barang atau jasa dari perusahaan yang dapat memberikan pelayanan yang terbaik kepada pelanggan (UUD RI No 44 Thn 2009).Pelayanan kesehatan adalah hak yang didapatkan oleh setiap pasien, sebagaimana yang tertulis dalam UndangUndang Republik Indonesia Nomor 36 Tahun 2009 tentang kesehatan, pasal 5 ayat (2) bahwa "setiap orang mempunyai hak dalam memperoleh pelayanan kesehatan yang aman,bermutu, dan terjangkau". Kualitas pelayanan harustetap dijaga dan diupayakan agar kinerja tenaga kesehatan tetap baik, sehingga dapat memberikan pelayanan yang bermutu bagi pasien. Oleh karena itu untuk melaksanakan seluruh kegiatan pelayanan tersebut sangat erat kaitannya dengan profesionalisme staf rumah sakit, termasuk kegiatan pelaynan keperawatan (Ratanto dkk., 2013).

Keperawatanmenjadi ujung tombak pelayan kesehatan dan sering digunakan menjadi patokan dalam menilai kualitas pelayanan kesehatan yang bermutu. Jumlah tenaga keperawatan menduduki peringkat teratas yang mencapai 49\% (296.876) dari jumlah tersebut berdasarkan jenis kelamin, perempuanlah yangterbanyak yaitu sebesar $71 \%$ sedangkan laki laki sebesar $29 \%$. Tenaga keperawatan yang didayagunakan di Rumah Sakit sebesar 29,46\% dan untuk puskesmas sebesar $12,22 \%$. Perawat yang kompeten menjadi syarat mutlak dalam memberikan pelayanan kesehatan saat ini dikarenakan perkembangan masyarakat yang semakin kritis seiring meningkatnya pengetahuan masyarakat mengenai kesehatan, upaya peningkatan mutu pelayanan kesehatan tidak bisa lepas dari upaya peningkatan mutu keperawatan. Oleh sebab itu perawat sebagai tim pelayanan kesehatan yang terbesar dituntut untuk meningkatkan mutu pelayanan keperawatan (BPPSDMK, Kemenkes RI, 2017)

Kinerja perawat memiliki nilai yang vital dan strategis. Menurut penelitian (Hafid, A, M. 2014) didapatkan hubungan yang signifikan antara kinerja perawat dengan kepuasan pasien,sehingga bisa dilihat peranan penting perawat dalam pelayanan di rumah sakit. Hal ini disebabkan karena perawat secara kuantitas adalah tenaga terbanyak di rumah sakit yaitu berjumlah 60,55\% (Kemenkes, (2010). Menurut hasil studi dari Direktorat Keperawatan dan keteknisan Medik Depkes UGM dan WHO yang melakukan penelitian di empat provinsi yaitu Jakarta, Sumatera Utara, Sulawesi Utara dan Kalimantan Timur, ditemukan data bahwa $47,4 \%$ perawat belum memiliki uraian tugas secara tertulis, $70,9 \%$ perawat tidak pernah mengikuti pelatihan selama tiga tahun terakhir, 39,8\% perawat masih melaksanakan tugas non keperawatan serta belum dikembangkan sistem monitoring dan evaluasi kinerja perawat.

Kajian yang telah dilakukan Direktorat Pelayanan Keperawatan Depkes RI (2017) menunjukkan pelayanan keperawatan yang diberikan perawat kepada klien masih jauh dari harapan. Penelitian Sukoco (2001) didapat tingkat kepuasan klien mencapai $72,6 \%$, demikian pula penelitian yang dilakukan oleh Oroh, dkk., (2014), didapatkan bahwa kepuasan pasien $73 \%$. Penelitian Hafid, A, M. (2014) tentang hubungan kinerja perawat dengan kepuasan pasien menunjukan 21 orang $(70,0 \%)$, Penelitian Widayanti D. (2017) tentang kinerja perawat munujukan cukup baik $41,8 \%$, penelitian tersebut sejalan dengan penelitian Nurhidayah (2018) tentang kinerja perawat dengan 73 responden menunjukan kinerja yang kurang baik $47,9 \%$ atau 35 orang dari hasil tersebut menunjukkan terdapat kelemahan 
dalam pelayan keperawatan yang harus diperbaiki di rumah sakit.

Faktor-faktor yang mempengaruhi kinerja perawat berdasarkan psikososial yang menggambarkan seseorang dengan kesehatan emosional yang nampak dalam kepribadian sehingga muncul niat dalam bekerja (Nursalam, 2012). Kinerja masingmasing orang berbeda karena dalam bekerja masing-masing individu memiliki kepribadian orang berbeda-beda, oleh karna itu dari tipe kepribadian masingmasing orang berbeda maka hasil kerjanyapun tentu akan berbeda-beda (Nisha dan Arum, 2011).Menurut Suryabrata,S (2002), tipe kepribadian seseorang dapat dibedakan menjadi dua, yaitu kepribadian ektrovert dan kepribadian introvert. Tipe kepribadian yang dimiliki akan memengaruhi seorang perawat menghadapi tuntutan dan stressor yang mungkin muncul dalam pekerjaan.

Berdasarkan pendataan awal dilakukan peneliti pada bulan November 2018 di ruangan rawat Inap RSU GMIM Bethesda Tomohon. Hasil wawancara dengan 6 pesien, didapatkan 2 pasien mengatakan masih kurang puas dengan pelayanan yang ada dengan alasan perawat yang ada di ruangan memiliki pembawaan yang berbeda-beda, seperti komunikasi yang kurang menunjukan sikap yang ramah dalam melakukan tindakan keperawatan, ada juga perawat yang dalam melakukan tindakan mempunyai sikap dan komunikasi yang baik. Jumlah ruangan rawat inap ada 8 dengan jumlah perawat 89 orang dengan tingkat pendidikan D3 dan 18 dengan tingkat pendidikan S1 dan Ners. Berdasarkan uraian diatas maka peneliti tertarik untuk meneliti tentang hubungan tipe kepribadian dengan kinerja perawat di ruangan rawat Inap RSU GMIM Bethesda Tomohon".

\section{METODE PENELITIAN}

Penelitian ini termasuk dalam jenis penelitian kuantitatif dengan menganalisis gambaran hubungan antara kedua variabel yaitu variabel independen (Tipe
Kepribadian) dan variabel dependen (Kinerja Perawat). Penelitian ini menggunakan desain penelitian cross sectional. Penelitian ini dilaksanakan di RSU Bethesda Tomohon pada tanggal 21 Januari 2019.Populasi penelitian ini adalah seluruh perawat dengan strata pendidikan D3 dengan jumlah 89. Pengambilan sampel menggunakan teknik Total sampling maka didapatkan jumlah sampel yang memenuhi kriteria inklusi 62 sampel.

Instrumen penelitian yang digunakan untuk mengukur variabel Tipe kepribadian menggunakan kuesioner yang digunakan sebelumnya oleh Kristiyani, M, Y. (2009) yang telah diuji validitasnya. kuesioner tipe kepribadian menggunakan skala guttman yang terdiri dari dua alternatif jawaban dengan pembagian penilaian yaitu, untuk pertanyaan memihak diberi skor 1 untuk jawaban "Ya" dan skor 0 untuk jawaban "Tidak", dan untuk pertanyaan tidak memihak diberi skor 0 untuk jawaban "Ya" dan skor 1 untuk jawaban "Tidak".Kuesioner ini terdiri dari 42 pernyataan yang terdiri dari Activity (12 pernyataan) Risk-taking (6 pernyataan),Impulsiveness (6pernyataan), Expessiveness (6 pernyataan), Reflectiveness (6 pernyataan), Responsibility (6 pernyataan). Tipe kepribadian dihitung jumlah cut of point dan didapatkan hasil dikatakan tipe kepribadianEkstrovert : jika nilai responden $\geq$ cut of point (21), dan dikatakan tipe kepribadian introvert : jika nilai responden < cut of point (21). Kuesioner diisi oleh responden kemudian dilakukan penghitungan skor dengan cara menjumlahkan skor tiap pertanyaan. Untuk menentukan tipe kepribadian dihitung dari jumlah skor tertinggi pada 2tipe kepribadian.

Kuesioner yang kedua (kinerja perawat) di kutip dari Royani, (2010) yang terdiri dari 25 pernyataan, dibagi menjadi pernyataan positif (Favorabel) dan pernyataan negatif (unfavorabel) dengan pengkajian (6 pernyataan), Diagnosa Keperawatan (3 pernyataan), perencanaan 
(4 pernyataan), pelaksanaan (7 pernyataan), evaluasi (5 pernyataan).Kuesioner ini menggunakan empat alternatif jawaban yang merupakan rentang skala kinerja yaitu: $1=\mathrm{TP}$ (tidak pernah), apabila pernyataan tersebut tidak perna dilakukan sama sekali; $2=\mathrm{J}$ (jarang), apabila pernyataan tersebut jarang dilakukan (lebih sering tidak dilakukan); $3=\mathrm{S}$ (sering), apabila pernyataan tersebut sering di lakukan (jarang tidak digunakan); 4=SL (selalu), apabila pernyataan tersebut selalu dilakukan (tidak pernah/tidak dilakukan).

Kinerja perawat dihitung jumlah cut of point dan didapatkan hasil dikatakan kinerja baik : jika nilai responden $\geq$ cut of point (62.5), dan dikatakan kinerja kurang baik: jika nilai responden < cut of point (62.5).Penelitian ini diolah secara manual dengan mengelompokkan hasil kuesioner kemudian dilakukan penghitungan skor dan dianalisis menggunakan uji statistik melalui sistem komuterisasi dengan beberapa tahap yaitu selecting,editing, coding, tranfering, tabulating. Analisa bivariat dalam penelitian ini yaitu untuk mengetahui hubungan tipe kepribadian dengan kinerja perawat di ruangan rawat inap RSU GMIM Bethesda Tomohon. Peneliti menggunakan uji statistic ChiSquaredengan tingkat kemaknaan 95\% ( $\alpha$ $=0,05)$.

HASIL dan PEMBAHASAN

1. Karakteristik Responden

Tabel 1. Distribusi Sampel Berdasarkan Jenis Kelamin

\begin{tabular}{lll}
\hline Jenis Kelamin & $\mathbf{n}$ & \% \\
\hline Laki-laki & 8 & 12.9 \\
Perempuan & 54 & 89.1 \\
\hline Total & $\mathbf{6 2}$ & $\mathbf{1 0 0 . 0}$
\end{tabular}

Sumber : Data Primer 2019

Hasil penelitian menunjukkan bahwa sebagian besar sampel memiliki jenis kelamin perempuan sebanyak 54 orang dengan presentase $89,1 \%$. Hasil penelitian sebelumnya yang dilakukan oleh Indriana tahun 2013 tentang faktor yang berhubungan dengan kinerja perawat didapatkan bahwa kebanyakan responden berjenis kelamin perempuan dengan presentase $86,8 \%$.

Tabel 2. Distribusi Sampel Berdasarkan Usia

\begin{tabular}{lll}
\hline $\begin{array}{l}\text { Umur } \\
\text { (tahun) }\end{array}$ & $\mathbf{n}$ & $\%$ \\
\hline $25-35$ & 41 & 66.1 \\
$35-45$ & 11 & 17.7 \\
$46-55$ & 9 & 14.5 \\
$56-65$ & 1 & 1.6 \\
\hline
\end{tabular}

\begin{tabular}{lcc}
\hline Total & $\mathbf{6 2}$ & $\mathbf{1 0 0 . 0}$ \\
\hline Sumber : Data Primer 2019 &
\end{tabular}

Hasil penelitian ini menunjukan responden berusia 25-35 tahun sebanyak $66,1 \%$ dari total responden. Menurut Kumbadewi (2016) usia produktif seorang pekerja berada dalam rentang 15-65 tahun dan menurut Depkes tahun 2012 pada rentang usia 26-35 masuk pada masa dewasa awal sehingga dapat terlihat responden dalam penelitian ini terbanyak pada usia produktif. Usia seseorang mempengaruhi tingkat produktivitasnya, ketika memasuki lanjut usia maka produktivitasnya menurun karena dipengaruhi faktor seperti fisik dan status kesehatannya. 
Tabel 3. Distribusi Sampel Berdasarkan Lama Kerja

\begin{tabular}{lll}
\hline $\begin{array}{l}\text { Lama Kerja } \\
\text { (tahun) }\end{array}$ & $\mathbf{n}$ & $\mathbf{\%}$ \\
\hline$<6$ & 20 & 32.3 \\
$6-10$ & 17 & 27.4 \\
$>10$ & 25 & 40.3 \\
\hline Total & $\mathbf{6 2}$ & $\mathbf{1 0 0 . 0}$ \\
\hline
\end{tabular}

Sumber : Data Primer 2019

Berdasarkan lama kerja lebih dari 10 tahun sebesar $40,3 \%$ dari total 62 responden merupakan jumlah terbanyak pada penelitian ini. Hasil penelitian Indriana tahun 2013 tentang faktor yang berhubungan dengan kinerja perawat didapatkan bahwa kebanyakan responden memiliki lama bekerja 1-5 tahun sebanyak 46 perawat $(67,6 \%)$. Menurut Manorek tahun (2018), lama bekerja bisa mempengaruhi kinerja seseorang. Semakin lama seseorang bekerja tentunya semakin baik pula kinerja yang bisa dihasilkan seseorang.

\section{Analisa Univariat}

Tabel 4. Distribusi Sampel Berdasarkan Tipe Kepribadian

\begin{tabular}{lll}
\hline $\begin{array}{l}\text { Tipe } \\
\text { Kepribadian }\end{array}$ & n & \% \\
\hline Ekstrovert & 31 & 50 \\
Introvert & 31 & 50 \\
\hline Total & $\mathbf{6 2}$ & $\mathbf{1 0 0 . 0}$ \\
\hline
\end{tabular}

Sumber : Data Primer 2019

Hasil penelitian menunjukkan bahwa dari tipe kepribadian introvert 31 (50\%) dan ektrovert $31 \quad(50 \%)$ responden. Kepribadian menunjukan pada sifat umum masing-masing individu yang membedakan dia antara yang lain yang menjadi menjadikan masing-masing individual indentik, bisa jadi memiliki sifat-sifat yang positif ataupun negatif, yang secara umum kepribadian seseorang akan berbeda-beda yang dibawah sejak lahir seperti kepribadian introvert yang cenderung pemalu yang lebih senang melakukan kegiatan sosial mereka sendiri namun juga introvert lebih suka menulis buku dan saat melakukan sesuatu akan memikirkannya dengan matang sebelum bertindak. Seseorang dengan kepribadian ekstrovert lebih menyukai lingkungan yang interaktif dan suka dengan hal-hal yang baru dan mereka lebih terbuka dengan orang lain disekitarnya namun juga mereka lebih sedikit berpikir sebelum melakukan sesuatu (Suryabrata, S, 2002).

Tabel 5. Distribusi sampel berdasarkan Kinerja Perawat

\begin{tabular}{lll}
\hline $\begin{array}{l}\text { Kinerja } \\
\text { Perawat }\end{array}$ & n & \% \\
\hline Baik & 37 & 59.7 \\
Kurang Baik & 25 & 40.3 \\
\hline Total & $\mathbf{6 2}$ & $\mathbf{1 0 0 . 0}$ \\
\hline
\end{tabular}

Sumber : Data Primer 2019

Tabel 5 menunjukkan bahwa dari totalresponden didapat sebanyak $59.7 \%$ dengan kinerja baik dan $40.3 \%$ dengan kinerja kurang baik. Hal ini sejalan dengan penelitian yang dilakukan oleh Ridho (2015) dengan jumlah responden 73 orang dengan kinerja baik $57 \%$ dan kinerja kurang baik $43 \%$ yang menunjukan kinerja seorang perawat lebih dominan yang kinerjanya lebih baik ketimbang kinerja yang kurang baik sehingga kualitas pelayanan dalam suatu instansi penyedia jasa layanan kesehatan tetap baik, sehingga memunculkan kepuasan pasien terhadap sebuah instansi kesehatan. Presentasi kinerja perawat yang kurang baik pada $40.4 \%$ akan ada saja pasien yang kurang puas terhadap pelayanan kesehatan yang diberikan khususnya pelayanan keperawatan, penelitian dari Ridho (2015) faktor yang mempengaruhi kinerja perawat seperti motivasi kerja, stres kerja, pengalaman kerja, dan sikap adalah diterminan perilaku yang bisa dikaitkan 
dengan kepribadian seseorang juga mempengaruhi kinerja seorang perawat.

\section{AnalisaBivariat}

Tabel 6. Hubungan Tipe Kepribadian dengan Kinerja Perawat di ruangan rawat inap RSU GMIM Bethesda Tomohon

\begin{tabular}{lcccc}
\hline \multirow{2}{*}{$\begin{array}{c}\text { Tipe } \\
\text { Kepribadian }\end{array}$} & \multicolumn{3}{c}{ Kinerja Perawat } & \\
\cline { 2 - 4 } & Baik & $\begin{array}{l}\text { Kurang } \\
\text { Baik }\end{array}$ & Total & \\
\hline Introvert & 24 & 7 & 31 & \\
Ekstrovert & 1 & 30 & 31 & 0.000 \\
\hline Total & 25 & 37 & 62 & \\
\hline
\end{tabular}

Sumber : Data Primer 2019

Tabel 6 hasil uji hipotesis dari tipe kepribadian dengan kinerja perawat menggunakan uji statistik Chi-square pada tingkat kemaknaan $95 \%(a=0,05 \%)$, dari hasil penelitian yang telah dilakukan menunjukkan adanya hubungan tipe kepribadian dengan kinerja perawat di ruangan rawat inap RSU GMIM Bethesda Tomohon Dimana nilai $\mathrm{P}=0,000$ lebih kecil dari $\mathrm{a}=0,05$. Dengan demikian sesuai dengan dugaan awal penulis bahwa terdapat hubungan tipe kepribadian dengan kinerja perawat. Analisa hasil crosstab dengan menggunakan uji Chi-Square, berdasarkanhasilpenelitian, 6 menunjukkan bahwa dari 31 responden yang memiliki tipe kepribadian introvert, 24 responden (38.7\%) dikategorikan kurang baik dalam kinerjanya sebagai perawat dan 7 responden $(11.3 \%)$ dikategorikan baik dalam kinerjanya.

\section{SIMPULAN}

Tipe kepribadian Perawat di Ruangan Rawat Inap RSU GMIM Bethesda Tomohon mempunyai presentasi yang sama antara kepribadian ekstrovert dan introvert.Kinerja Perawat di Ruangan Rawat Inap RSU GMIM Bethesda Tomohon paling banyak menunjukkan kinerja yang baik (59.7\%)Terdapat hubungan yang signifikan antara tipe kepribadian dengan kinerja Perawat di Ruangan Rawat Inap RSU GMIM Bethesda Tomohon.

\section{DAFTAR PUSTAKA}

Hafid, A, M. (2014) Hubungan Kinerja Perawat Terhadap Tingkat Kepuasan Pasien Pengguna Yankestis Dalam Pelayanan Keperawatan Di Rsud Syech Yusuf Kab.Gowa. Fakultas Keperawatan Universita Islam Negeri Alauddin Makasar.

Indriana S, D. (2013). Faktor Yang Berhubungan Dengan Kinerja Perawat di Ruangan Rawat Inap RS Ibnu Sina YBW-UMI Makasar. Fakultas Kesehatan Masyarakat Universitas Hasanuddin Makasar.

Kemenkes RI, (2010) Profil Kesehatan Indonesia Jakarta: Badan Penelitian dan pengembangan Kesehatan Kementrian Kesehatan RI.

Kemenkes RI, (2017) Badan pengembangan sumber daya manusia kementrian kesehatan RI.

Direktorat Pelayanan Keperawatan Depkes RI (2017)) Info Datin Situasi Tenaga Keperawatan Indonesia Jakrta Selatan :Pusat Data dan Informasi Kementrian Kesehatan RI.

Kristiyani,M,Y. (2009) Hubungan Antara Tipe Kepribadian EkstrovertIntrovert Dengan Orientasi Ketrampilan Komunikasi Interpersonal Pada Distributor Multi Level Marketing Tianshi. Fakultas Psikologi Universitas Sanata Dharma Yogyakarta.

Kumbadewi, Suwendra, Susila (2016) Pengaruh Umur, Pengalaman Kerja, Upah, Teknologi dan Lingkungan Kerja Terhadap Produktivitas Karyawan. Jurusan Manajemen Universitas Pendidikan Genesha Singaraja Indonesia.

Manorek, H. (2018) Faktor-faktor yang Berhubungan dengan penerapan 
Sasaran Keselamatan Pasien pada Perawat di ruangan rawat inap Rumah Sakit Umum Daerah Dr. Sam Ratulangi Tondano.

Nisha dan Arum (2011) Hubungan antara tipe keprbadian dengan kinerja perawat di rumah sakit PKU Muhammadyah Surakarta.

Nurhidayah (2018) Hubungan Knowledge Management Dengan Kinerja Perawat Di Ruangan Rawat Inap Rumah Sakit Unhas Makasar. Jurusan Keperawatan Stikes Hasanuddin Makasar.

Nursalam, (2012) Manajemen Keperawatan: Aplikasi dalam bentuk Praktik Keperawatan Profesional. Edisi 3.Jakarta.

Oroh, Rompas, Pondaag ,(2014)Faktorfaktor yang berhubungan dengan Tingkat Kepuasan Pasien Rawat Inap terhadap pelayanan Keperawatan di ruang Interna Rsud Noongan, Program Studi Ilmu Keperawatan Fakultas Kedokteran Universitas Sam Ratulangi Manado

Ratanto,Mustikasari,Kuntarti

Pengembangan karier sebagai factor palingmemengaruhi kinerja perawat pelaksana

http://jki.ui.ac.id/index.php/jki/article /view/10/10 di akses tanggal 1 oktober 201813.00 wita .

Ridho, M. (2015). Faktor-faktor Yang Mempengaruhi Kierja Perawat Pelaksana Di Rumah Sakit Bhayangkara Tingkat IV Kendari. Bagian Aministrasi RS FKM Universitas Hasanuddin Makasar.

Royani (2010) Hubungan Sistem Penghargaan dengan Kinerja Perawat dalam Melaksanakan Asuhan
Keperawatan di RSUD Cilegon Banten. Program Pasca Sarjana Universitas Indonesia .

Sukoco, A.S. (2001). Perbedaan persepsi perawatdengan klien terhadap kualitas pelayanan keperawatan di RSPAD Gatot Soebroto JakartaFakultas Ilmu Keperawatan Universitas Indonesia, Jakarta.

Suryabrata, Sumadi. 2002. Psikologi Pendidikan. Jakarta: PT. Grafindo Perkasa Rajawali.

Undang-Undang Republik Indonesia No 44 Tahun 2009 Pasal 1 tentang rumah sakit.

Widayanti, D. (2017) Hubungan Beban Kerja dengan Kinerja Perawat di ruang rawat inap kelas III RSUD wates. Stikes Jenderal Achmad Yani Yogyakarta. 